\section{EMBRYRIDDLE \\ Aeronautical University}

SCHOLARLY COMMONS
International Journal of Aviation, Aeronautics, and Aerospace

8-1-2014

\title{
A total-energy based model of airplane overspeed takeoffs
}

Nihad E. Daidzic

AAR Aerospace Consulting LLC, aaraerospace@cs.com

Follow this and additional works at: https://commons.erau.edu/ijaaa

\section{Scholarly Commons Citation}

Daidzic, N. E. (2014). A total-energy based model of airplane overspeed takeoffs. International Journal of Aviation, Aeronautics, and Aerospace, 1(3). https://doi.org/10.15394/ijaaa.2014.1016

This Article is brought to you for free and open access by the Journals at Scholarly Commons. It has been accepted for inclusion in International Journal of Aviation, Aeronautics, and Aerospace by an authorized administrator of Scholarly Commons. For more information, please contact commons@erau.edu, wolfe309@erau.edu. 
Takeoff calculations for the Federal Aviation Administration (FAA) FARs (Federal Aviation Regulations) or European Aviation Safety Agency (EASA) CS (Certification Standards Document) Part 25 certified airplanes operating in commercial service, such as, under FAA FAR Part 121 (Holt \& Poynor, 2006) are extremely complex (Daidzic, 2013a, 2013b; Eshelby, 2000; Padilla, 1996; \& Swatton, 2008). Approved Airplane Flight Manual (AFM) takeoff data is based on measured and demonstrated performance during aircraft flight testing and certification rather than on mathematical models with computational predictions and simulations (Asselin, 1997; Daidzic, 2013b; Eshelby, 2000; FAA, 1994; Jeppesen, 2007; Padilla, 1996; \& Swatton, 2008). Linear interpolation between certified measured AFM takeoff data is permissible in most instances, while extrapolation of any form almost never is. Mathematical models of aircraft performance are very useful in predicting and estimating performance in development and design phase, but cannot be used as a substitute for certified measured data.

Inverse methods of Takeoff Weight (TOW) estimation are used for weight calculations in scheduled air-transportation. Airport, runway, and environmental conditions: wind, temperatures, humidity, etc., are given and measured with a known degree of uncertainty (error) and the Maximum Allowable TOW (MATOW) is then calculated based on the gross performance capabilities restricted and diminished by operational regulations to account for net performance safety margins. To calculate performance-limited MATOW or Regulated-TOW (RTOW), the entire flight from takeoff to landing at alternate airport (and beyond) must be considered (Daidzic, 2013b; Eshelby, 2000; Jeppesen, 2007; \& Swatton, 2008) with safety regulations determining minimum acceptable performance level at each phase of flight: takeoff, climb, cruise, descent, approach \& landing. Airplane TOW is an essential parameter in aircraft performance.

In commercial air transportation where services are offered to general public only FAR/CS 25 certified airplanes are employed (EASA 2007; JAA, 2007; \& FAA, 2013), which, among other issues guarantees certain minimum level of performance in case of engine failure, i.e., One Engine Inoperative (OEI ) at any point during flight (Daidzic, 2013b; Eshelby, 2000; Jeppesen, 2007; \& Swatton, 2008). Although actually rare (FAA, 1994), engine-failure must be assumed in every takeoff calculation. A failure to account for would result in unacceptably high levels of risk. A myriad of takeoff conditions exist with varying runway lengths, clearways and stopways, slopes, surface quality and condition and atmospheric conditions. Takeoffs and landings are the most critical phase of flight operation that expose an operator to a number of adverse 
conditions and hazards (Daidzic \& Shrestha, 2008; Daidzic, 2008, 2009a, 2009b, 2011a, 2013a; \& FAA, 1994).

Aircraft gross and/or net performance (as appropriate per regulations) must ensure that either continued Accelerate-Go (AG) or Rejected (RTO) Accelerate-Stop (AS) takeoffs can be accomplished at any instant during takeoff roll and that safe climbs will be achieved in an AG OEI case. Considering takeoff and initial climb an aircraft TOW can be restricted by Field-Length Limited TOW (FLLTOW), still-air Climb Limited TOW (CLTOW), or Obstacle Limited TOW (OLTOW).

MATOW or RTOW is limited or by some structural limitation, such as, Maximum Zero-Fuel Weight (MZFW), Maximum Structural TOW (MSTOW), Maximum Structural Landing Weight (MSLW), or by any of many Performance Limited TOWs (PLTOWs). When the actual Takeoff Distance Available (TODA), Takeoff Run Available (TORA), Accelerate-Stop Distance Available (ASDA) or Gradient of Climb (GOC) is not limiting, then reduced/de-rated thrust takeoffs are possible (Daidzic, 2012; \& FAA, 1994). Often this is a Standard Operating Procedure (SOP) with maximum Takeoff/Go-Around thrust (TOGA) takeoffs being an exception in some specific cases (Daidzic \& Shrestha, 2008; \& Daidzic, 2012, 2013a).

However, sometimes it happens that MATOW is not field, but climb or obstacle clearance limited. In that case it is often possible to increase the original climb-gradient-limited TOW somewhat by utilizing unused runway to increase takeoff speeds in order to reduce aerodynamic drag and improve subsequent airplane climb performance.

An interesting takeoff scenario could thus exist when an airplane is CLTOW or OLTOW limited. If the FLLTOW is markedly higher than CLTOW or OLTOW, unused runway can be utilized to "pump" more energy into, and accelerate, aircraft to higher $V_{1}$ (takeoff decision/action speed), $V_{R}$ (takeoff rotation speed), $\mathrm{V}_{\text {LOF }}$ (takeoff liftoff speed), and $\mathrm{V}_{2}$ (takeoff safety speed) to achieve steeper climb gradients. In that case new MATOW can be increased until an aircraft becomes simultaneously field and climb (and/or obstacle) limited. The new MATOW will be somewhere between the original FLLTOW (does not meet climb requirements) and CLTOW (significant weight penalty), i.e., CLTOW < MATOW < FLLTOW. This is the basic idea behind overspeed or improved-climb or improved- $\mathrm{V}_{2}$ takeoffs. Since TOW is given and thrust on the remaining engine is at maximum the only change that one has some control over is airplane drag. 
Surprisingly little is known or published on overspeed takeoffs. To the best of our knowledge no relevant publication from any regulatory agency or from existing archived academic literature exists. Only cursory information is found in some aircraft performance and operations books specifically designed for students and aviation professionals (Jeppesen, 2007; Padilla, 1996; \& Swatton, 2008). Aerospace and/or aeronautics engineering books on aircraft performance with emphasis on takeoffs carry absolutely no information on overspeed takeoffs. Even the specific takeoff-oriented informational publications by regulatory agencies and various national and international aviation safety organizations provide no facts on this important topic. It seems that any practical calculations and applications of overspeed takeoffs is only considered by aircraft manufacturers relaying on extensive measured performance and flight testing and as such is a proprietary information. Therefore, this article is an attempt to highlight the basic physics and philosophy behind overspeed takeoffs and provide analytical methods for quick estimates.

The problem of overspeed takeoffs is also intimately tied to the question of optimal flap setting for given runaway, environment and Obstacle Accountability Area (OAA). There is no general mathematical solution and different situations will need diverse answers. In practice, certified airplane performance and runway/airport approved data combined with environmental conditions is all put together in a simple form (print and/or digital) called "runway/airport analysis charts" which summarizes complex calculations and partial optimizations.

Finding the optimum flap setting for given takeoff conditions is not a simple task. Conflicting requirements exist. More flaps and liftoff distance is shorter or more weight can be lifted for the same runway. However the subsequent climb gradient suffers dramatically and airplane may not clear obstacles in takeoff path or meet still-air Weight-Altitude-Temperature (WAT) climb gradients.

The effect of flap setting on a generic modern turbofan airplane TOW and its various limitations are illustrated in Figure 1. All other variables are fixed in this particular illustration which by no means is representative of all possible takeoff scenarios. Typical modern commercial jet does not have as many different flap/slat settings as depicted, but this illustration serves to better understand varying TOW limitations. At first the effect of flap increases FLLTOW (Jeppesen, 2007), but after reaching maximum it starts decreasing due to steep increase in coefficient-of-drag $\left(C_{D}\right)$. Any flap/slat setting will produce higher $C_{D}$ than a clean wing causing reduced climb gradients. 
The irony of airplane takeoffs is illustrated in Figure 2. What is the optimum flap setting for given weight and thrust? By deploying more flaps (e.g., $20^{\circ}$ ) the airplane will get airborne earlier, but the subsequent climb (out of ground effect) will be very shallow and the obstacle clearance may be in serious doubt. Using low flap-setting $\left(5^{0}\right)$ will result in significantly steeper GOC, but the liftoff will be further down the runway thus possibly violating TODA/TORA and perhaps not being able to clear near obstacles. At some point from the runway these two extreme scenarios will result in the same height above Reference Zero (RZ) and lower flap setting will definitely be more beneficial from there on. In a sense one trades long-term goals with short-term necessities. Mathematical theory of optimization can be used to find answers to particular takeoff problem.

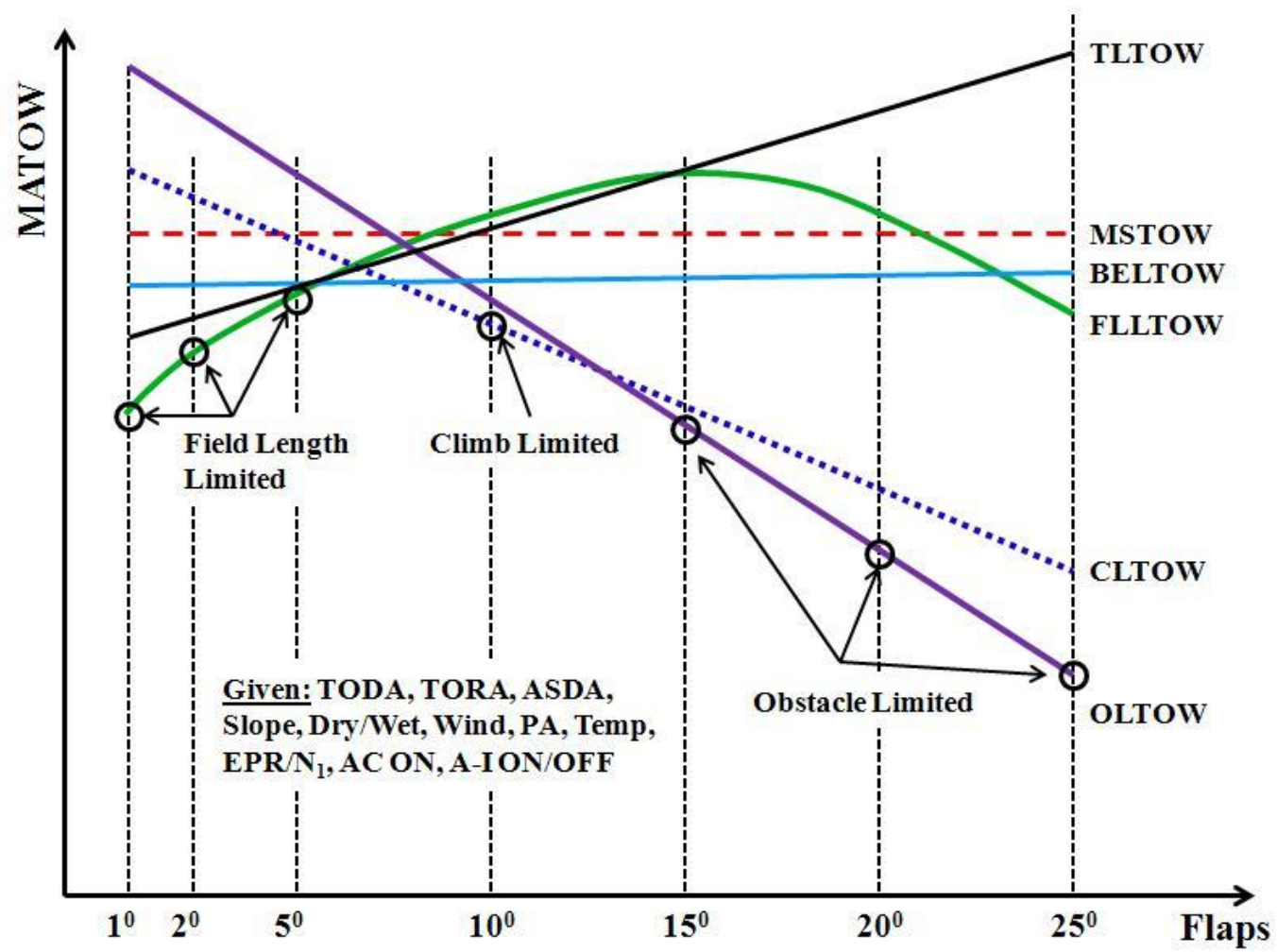

Figure 1. MATOW versus flap setting. Brake Energy Limited TOW (BELTOW), Tire (speed) Limited TOW (TLTOW). Not to scale.

For obstacle clearance, a net-flight path must clear all obstacles by $35 \mathrm{ft}$ vertically and is, for example, $0.8 \%$ lower than the required minimum gross of $2.4 \%(1.6 \%$ net $)$ in the critical $2^{\text {nd }}$-segment climb for the twin-engine FAR/CS 25 
airplanes. If higher climb gradients are required, due to obstacles in the takeoff climb path (e.g., 3\% net), the gross gradient must be then $3.8 \%$ for twin-jets specifically when OEI. Thus, TOW often must be reduced in operational practice to meet individual climb requirements which directly affects profitability of operation.

Aerodynamic Efficiency $(\mathrm{E})$ is almost independent of weight and altitude for given configuration and angle-of-attack (AOA) below $\mathrm{V}_{\mathrm{MO}} / \mathrm{M}_{\mathrm{MO}}$ (MaximumOperating speed/Mach). A heavier airplane will need higher airspeed for the same optimum AOA. Additionally, thrust of modern high-bypass turbofans decreases significantly with the forward speed (propeller effect). For overspeed takeoffs one wants to increase $V_{2}$ to reduce drag and thereby increase excess thrust so that more weight can be lifted at prescribed minimum required climb gradient. Since thrust is already at maximum, increasing weight can only be compensated by increased $E$ which essentially means decreasing drag by increasing $\mathrm{V}_{2}$ to bring it closer to $\mathrm{V}_{\mathrm{X}}$ (steepest climb airspeed).

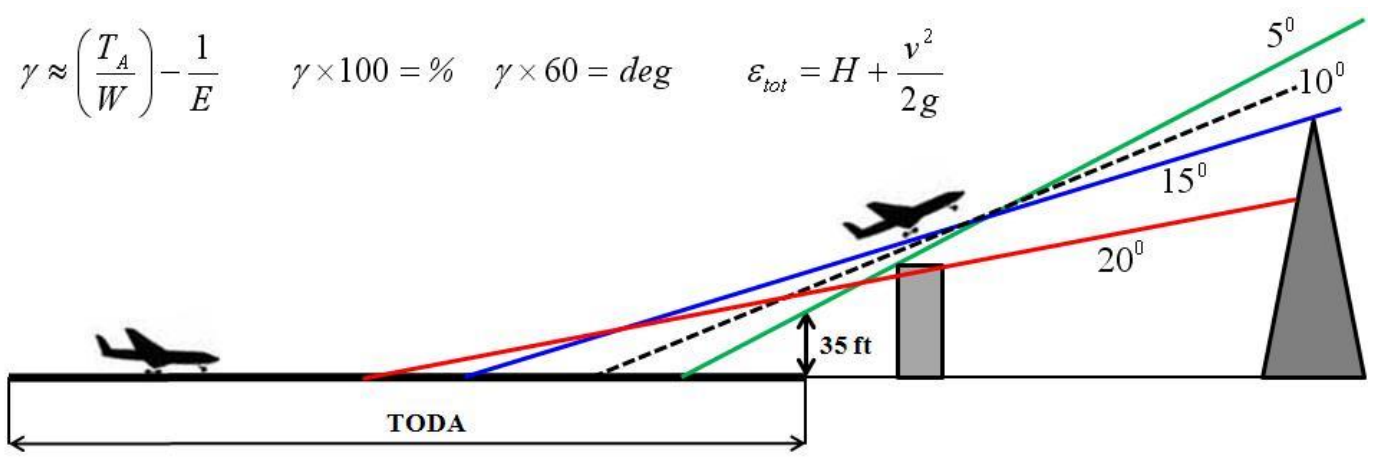

Figure 2. Takeoff optimization problem. Angles and distances highly exaggerated for better visual representation. Not to scale.

\section{Methods and Materials}

The reason for increased climb performance at higher $V_{2}$-speeds is clear when one remembers that $\mathrm{V}_{2}$ speed is only the takeoff safety speed specified to meet some basic control and performance criteria. One would think that it would be best to climb initially at $\mathrm{V}_{\mathrm{X}}$ (or OEI $\mathrm{V}_{\mathrm{X}}$ ) speed as that would guarantee steepest possible still-air gradient (angle). However, runway lengths would have to be excessive to accelerate to such high speeds provided other limitations are met. Most modern jet airplanes have $\mathrm{V}_{\mathrm{X}}$ in the range of 40-60\% above stalling speed in takeoff configuration, while $\mathrm{V}_{2 \mathrm{MIN}}$ (minimum $\mathrm{V}_{2}$ ) is only $20 \%$ above takeoff (stalling speed) $\mathrm{V}_{\mathrm{S} 1}$ (or 1.13 stalling reference speed $\mathrm{V}_{\mathrm{SR} 1}$ ). Having $\mathrm{V}_{2}$ equal to 
$\mathrm{V}_{\mathrm{X}}$ would essentially require $(1.6 / 1.2)^{2}$ or $78 \%$ longer runways. A typical commercial airliner today may have approximately (in CAS) at SL: $\mathrm{V}_{\mathrm{S} 1}$ of 130, $\mathrm{V}_{2 \mathrm{MIN}}=156, \mathrm{~V}_{2}=160, \mathrm{~V}_{\mathrm{X}}=205$, (minimum-drag speed) $\mathrm{V}_{\mathrm{MD}}=220$, and (maximum rate-of-climb airspeed) $\mathrm{V}_{\mathrm{Y}}=280$ knots. Due to decrease of thrust available with forward speed for modern turbofans, the $\mathrm{V}_{\mathrm{X}}$ is somewhat lower than $\mathrm{V}_{\mathrm{MD}}$ (see also functional condition given in Figure 3).

If airplane is CLTOW (< FLLTOW) limited, overspeed takeoff enables utilization of unused runway to increase (TOW improved) TOWi (> CLTOW). The original FLLTOW can never be reached as that would require the airplane to accelerate above speeds that just meet TODA requirements. A typical thrust-drag performance curves with overspeed mechanics highlighted are illustrated in Figure 3 with all engines operating (AEO) and OEI cases.

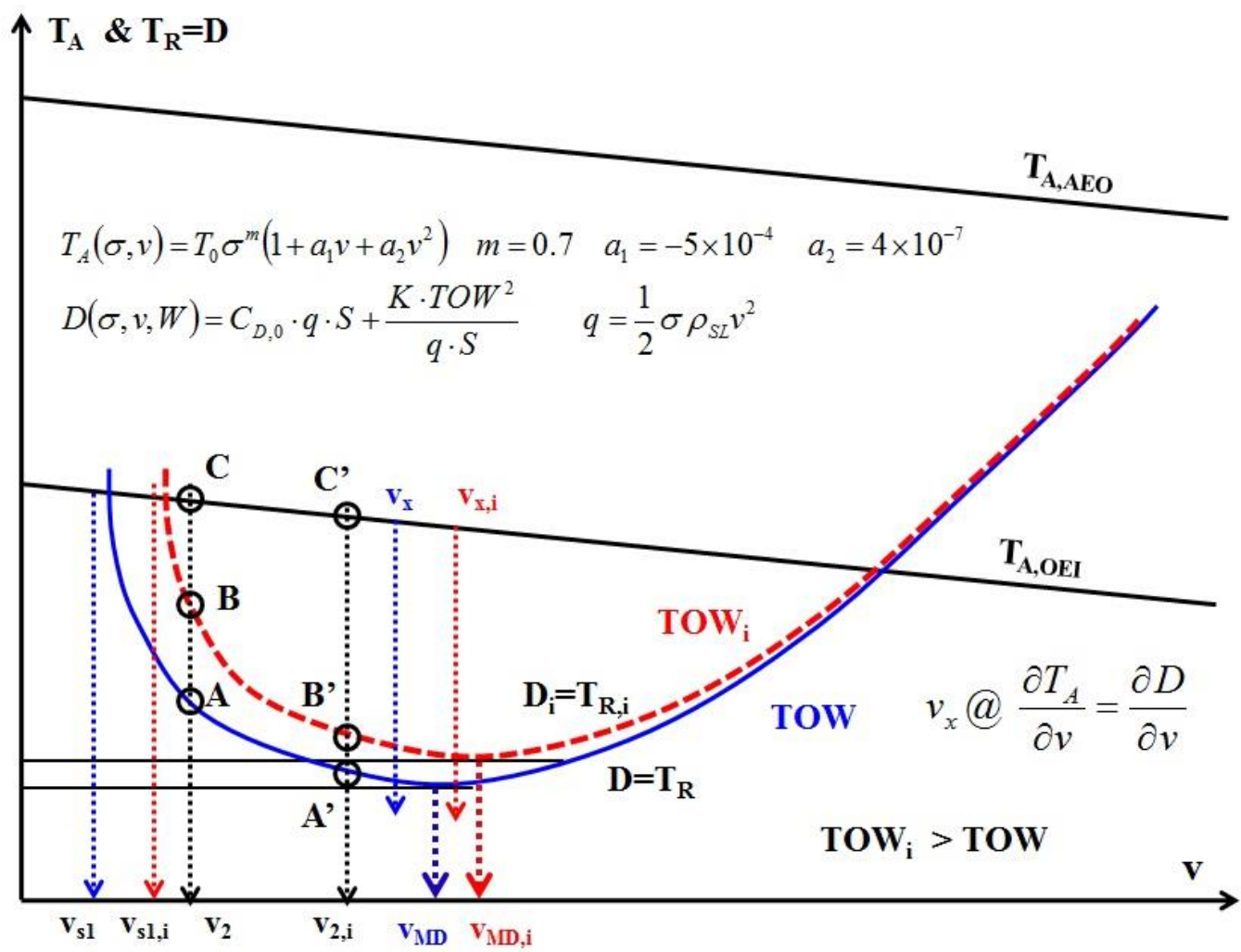

Figure 3. AEO and OEI thrust available and required thrust (drag) as a function of speed and TOW with typical modern turbofan engines. Not to scale. 
The original $\mathrm{V}_{2}$ speed for CLTOW limited-weight meeting required GOC is shown by line A-C (Figure 3). Increasing weight at old $\mathrm{V}_{2}$ causes significantly diminished excess of thrust (the line B-C) and very low OEI climb performance. Assume now the use of overspeed CLTOW takeoff with $\mathrm{V}_{2 \mathrm{i}}=\mathrm{V}_{2}+(10-20)$ knots at the initial lighter weight. In that case one obtains increased $-V_{2}$ or $V_{2 i}$ shown by line A'-C', which provides for more excess thrust. The basic idea is to increase $V_{2}$ to improve the climb-efficiency $E$ by reducing drag (lower AOA and coefficientof-lift $\mathrm{C}_{\mathrm{L}}$ ) thereby increasing excess thrust and GOC. But the airplane at original weight (CLTOW) will be now climbing in excess of GOC limitation which is not necessary. However, one could somewhat increase weight to TOWi > CLTOW in connection with this new $\left(\mathrm{V}_{2}\right.$ improved) $\mathrm{V}_{2 \mathrm{i}}$. In this case excess thrust shown by B'-C' is obtained which must be somewhat larger than A-C to lift more weight at the same required gradient. But how much can TOWi be increased to comply with the airfield and climb restrictions and how large $V_{2 i}$ need to be is a difficult question. The goal of this article is to show an analytical method of how this can be done.

Increased takeoff weight TOWi will have detrimental effect on drag-dueto-lift. As a consequence the $\mathrm{V}_{\mathrm{MD}}$ and total drag for heavier aircraft will move to the right and up thus reducing OEI excess thrust at new weight. The idea is now to utilize the unused TODA with CLTOW-limitation so that airplane becomes field-limited again (e.g., at Screen Height, $\mathrm{SH}=35 \mathrm{ft}$ dry or $15 \mathrm{ft}$ wet), but at higher $V_{2 i}$ speed. At $V_{2 i}$, the airplane will also have higher CLTOWi. By "overspeeding" takeoff an aircraft gains more kinetic energy by utilizing the entire TODA-distance. Thus, to lift more weight (TOWi > CLTOW) one needs significant increase of $\mathrm{V}_{2}$. A new balance will be achieved and most importantly the original MATOW=CLTOW @ $\mathrm{V}_{2}$ will increase to CLTOWi=MATOWi @ $\mathrm{V}_{2 \mathrm{i}}$ while meeting all limitations.

\section{Mathematical Model of Unaccelerated Airplane Climb}

The unaccelerated climb angle or gradient of climb (GOC) can be described with (Anderson, 1999; Asselin 1997; Eshelby, 2000; Mair \& Birdsall, 1992; McCormick, 1995; \& Padilla, 1997):

$$
\gamma(\sigma, v, W)=\frac{T(\sigma, v)-D(\sigma, v, W)}{W}
$$


Where small GOCs is assumed $\left(<15^{0}\right)$ which is certainly true when OEI. It is customary in industry to represent GOC in percentages (or angular degrees but not radians): $\gamma \times 100=\gamma[\%]$ and $\gamma \times 60 \approx \gamma[\mathrm{deg}]$.

Subsonic aerodynamic drag can be modeled using the conventional drag polar (Anderson, 1999; \& Eshelby, 2000):

$$
C_{D}=C_{D, 0}(M)+K(M) \cdot C_{L}^{2}
$$

where:

$$
\begin{aligned}
& K=k_{1}+k_{2}+k_{3} \\
& k_{3}=\frac{1}{\pi \cdot A R \cdot e} \quad A R=\frac{b^{2}}{S} \quad k_{1}=\frac{k_{3}}{3} \quad k_{2}=0 \quad \text { (zero wave drag) }
\end{aligned}
$$

It is important to remember that this is just a mathematical/physical model and that real airplanes will have drag characteristics deviating somewhat from it. Aspect ratios (AR) and span efficiency $(e)$ of commercial transport-category jets are typically 8 and 0.8 respectively. Wing span (b) is typically in the range of 100-160 feet. Induced-drag coefficient $\mathrm{K}$ and zero-lift drag coefficient $\mathrm{C}_{\mathrm{D}, 0}$ are functions of airplane configuration and Mach number $(M>0.6)$. There is actually almost no practical limit to how much one can complicate drag relationship for the entire aircraft especially if wave drag and transonic region is included. The total drag (excluding wave drag) is thus the sum of drag not-due-to-lift (mostly parasitic) and drag due-to-lift (mostly induced) (Anderson, 1999; Asselin 1997; Eshelby, 2000; Mair \& Birdsall, 1992; \& McCormick, 1995):

$$
\begin{aligned}
& D(v)=\frac{1}{2} \sigma \cdot \rho_{S L} \cdot v^{2} \cdot S \cdot C_{D}=C_{p} v^{2}+C_{i} v^{-2} \\
& C_{p}=\frac{1}{2} \sigma \cdot \rho_{S L} \cdot S \cdot C_{D, 0} \quad C_{i}=\frac{2 \cdot K \cdot S \cdot n^{2}}{\sigma \cdot \rho_{S L}} \cdot\left(\frac{W}{S}\right)^{2} \quad C_{i}>>C_{p}
\end{aligned}
$$

Stalling speed in a given takeoff configuration is achieved at the maximum $\mathrm{C}_{\mathrm{L}}$ :

$$
v_{s n}=\left(\frac{2 \cdot n \cdot W}{\sigma \cdot \rho_{S L} \cdot S \cdot C_{L, \max , 1 g}}\right)^{1 / 2}=\sqrt{n} \cdot v_{s, 1 g} \quad n=\frac{L}{W}
$$


Here, $n$ is the (vertical) load factor which in (AEO and OEI) takeoff and landing (flare) pitch rotations is in the range of 1.05-1.15, while maximum $\mathrm{C}_{\mathrm{L}, \max }$ is assumed for the takeoff configuration (Daidzic \& Shrestha, 2008).

Installed thrust of modern turbofan jet engines is a very complicated function of many parameters and airframe-engine integration. A conventional way to simulate turbofan thrust at maximum or high throttle settings is to consider it a simplified function of air density and forward (TAS) speed (Daidzic, 2012):

$$
T(\sigma, v)=T_{0} \cdot \sigma^{m} \cdot\left(1+a_{1} \cdot v+a_{2} \cdot v^{2}\right) \quad T_{0}=T_{S L, I S A}^{\text {static }} \quad a_{1}<0 \quad a_{2}>0
$$

Coefficient $a_{1}$ accounts for momentum drag while $a_{2}$ includes RAM compression effect and $m$ is typically 0.7 in troposphere and 1.0 in tropopause. Density ratio is obtained from the non-dimensional ideal-gas (air) equation for International Standard Atmosphere (ISA) troposphere as (Daidzic, 2012, 2013b; Eshelby, 2000; \& Padilla, 1996) with Pressure Altitude (PALT) in feet:

$$
\begin{aligned}
& \delta=\frac{p}{p_{S L}}=\left(1-6.87142 \times 10^{-6} \cdot P A L T\right)^{5.256} \\
& \delta=\sigma \cdot \theta \quad \sigma=\frac{\rho}{\rho_{S L}} \quad \theta=\frac{\vartheta}{\vartheta_{S L}}
\end{aligned}
$$

All the references are taken at ISA Sea-Level (SL) conditions. Using Equation 3 for parasitic and induced drag and Equation 5 for speed-dependent thrust production, one can estimate maximum in-flight weight to achieve required GOC from Equation 1, resulting in the following quadratic equation for unknown weight:

$$
A \cdot W^{2}+B \cdot W+C=0
$$

where:

$$
\begin{aligned}
& A(\sigma, v)=\frac{2 \cdot K}{\sigma \cdot \rho_{S L} \cdot S} \cdot \frac{1}{v^{2}} \quad B(\gamma)=\gamma_{O E I} \\
& C(\sigma, v)=-\left[T_{0} \cdot \sigma^{m} \cdot\left(1+a_{1} \cdot v+a_{2} \cdot v^{2}\right)-\frac{1}{2} \cdot \sigma \cdot \rho_{S L} \cdot S \cdot C_{D, 0} \cdot v^{2}\right]<0
\end{aligned}
$$


Fortunately, Equation 7 can be solved analytically. The maximum climb weight is now the first (real positive) of the two possible solutions (the other results in negative TOW):

$W=\frac{-B+\sqrt{D}}{2 \cdot A}>0 \quad D=B^{2}-4 \cdot A \cdot C$

The maximum climb weight will first increase with higher speeds, reaches top, and then starts decreasing. The calculations of CLTOW for various required gross GOCs $\left(2 \%, 2.8 \%\right.$ and 3.6\%) and given environmental conditions of $25^{\circ} \mathrm{C}$ dry air and local altimeter setting (QNH) of 30.22' $\mathrm{Hg}(1023.41 \mathrm{mbar}$ or hPa) at MSL elevation of 5,000 ft for an airplane similar to Gulfstream IV (1985-2003) with SL ISA 12,500 lb flat-rated engines and MSTOW=73,000 lb (Anderson, 1999) is shown in Figure 4. Line (not shown) connecting all TOW maxima represents $\mathrm{V}_{\mathrm{X}}$ speed which is also increasing with weight at constant altitude.

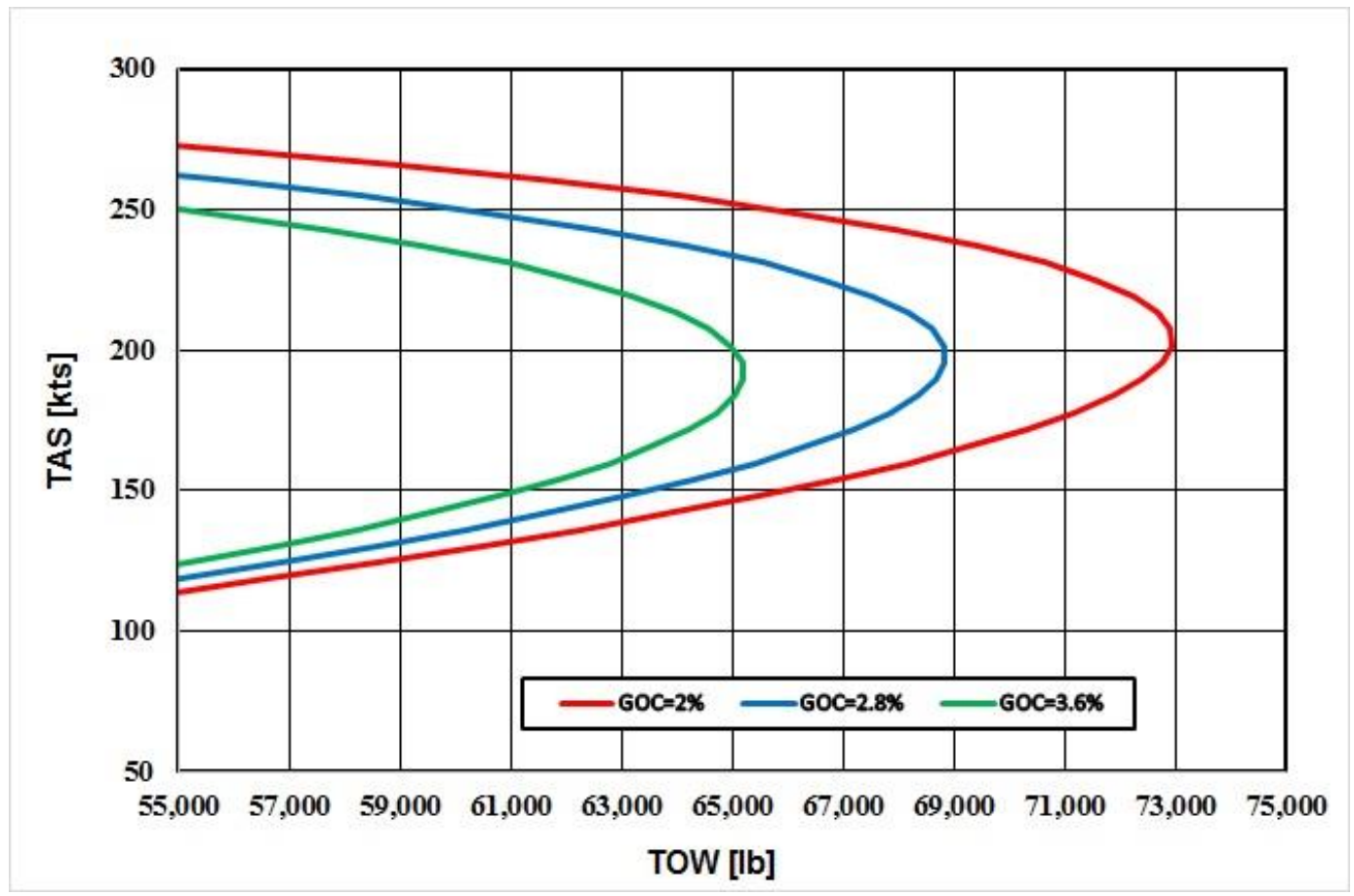

Figure 4. Calculated CLTOW as a function of (TAS) initial climb speed $\mathrm{V}_{2}$ for various required GOCs for an airplane type similar to Gulfstream IV. 


\section{Mathematical Model of Required Field Lengths}

Accelerated airplane motion is typically described by a 6-DOF (degreesof-freedom) rigid-body motion in an (approximate) inertial frame of reference utilizing $2^{\text {nd }}$ Newton's law of classical mechanics (Anderson, 1999; Asselin 1997; Daidzic \& Shrestha, 2008; Eshelby 2000; Mair \& Birdsall, 1992; \& McCormick, 1995). A model of linear acceleration requires detailed knowledge of all forces at every instant (or airspeed) along the takeoff run which is a very difficult task. A simplified standard non-orbiting "flat-earth" model with coupled nonlinear differential equations of accelerated motion used to calculate takeoff parameters during ground roll is:

$$
\begin{aligned}
& \frac{d s}{d t}=v \pm v_{w} \\
& \frac{d v}{d t}=\frac{g}{W}\left\{T(\sigma, v)-D(\sigma, v)-\mu_{R}(s) \cdot[W-L(\sigma, v)]-W \cdot \sin \varphi-\frac{v}{g} \frac{d W}{d t}\right\} \\
& \frac{d w}{d t}=\frac{g}{W}\{L(\sigma, v)-W \cdot \cos \varphi+N\}=0 \\
& \frac{d h}{d t}=w \\
& \frac{d W}{d t}=-T \cdot g \cdot \operatorname{SFC}(\theta, v)<0 \\
& I C s: \quad s=s_{0} \quad v=v_{0} \quad h=h_{0}=0 \quad w=w_{0}=0 \quad W=W_{0}=\text { MATOW }
\end{aligned}
$$

Average runway slopes $\varphi$ used in commercial air-transportation are typically less than $2 \%$ and sine and cosine functions can be linearly approximated for small angles. Rolling resistance is a function of the net weight (weight minus lift generated) at each wheel and depends on the tire as well as the runway surface conditions. The reaction thrust caused by burning fuel during takeoff is really very small and can be safely neglected. Wind speed (and direction) $V_{W}$ is assumed constant. Net vertical motion during ground roll is zero except for oscillations due to imperfect ground surface dampened by the wheels' shockabsorption system. The important effect of rotation and the accompanied steep rise of induced drag and the curious "elevator effect" (Daidzic, 2011b) was not considered. Nevertheless, this system of ordinary differential equations certainly can be integrated numerically (e.g., various Runge-Kutta and multistep methods) for known initial conditions (ICs), but that is cumbersome and dull work. Takeoff flight tests in instrumented airplanes are equally repetitive, time-consuming, and additionally very expensive. 
However, the main goal here is to obtain more physical insight. Thus, the energy balance (conservation) principle is more important and interesting for understanding overspeed takeoffs then just crunching numbers or performing repetitive tedious flight tests.

The ground roll distance is based on integration over acceleration history which on the other hand is a function of the TOW (assumed constant during takeoff) and the net balance force which is either speed-dependent or the net average-force which is constant throughout takeoff:

$$
\begin{aligned}
& s_{\text {LOF }}=\int_{0}^{v_{\text {LOF }}} \frac{v \cdot d v}{a(v)} \\
& a(v)=\frac{d v}{d t}=\frac{v d v}{d s}=\frac{d\left(v^{2} / 2\right)}{d s}=\frac{g \cdot F_{n e t}(v)}{W} \quad \bar{a}=\frac{g \cdot \bar{F}_{n e t}}{W}
\end{aligned}
$$

Closer inspection of the Equation 10 shows that this is just a statement of conservation of total energy (kinetic plus potential). If the average acceleration (and net force) during ground roll can be estimated, the lift-off distance becomes:

$$
\begin{aligned}
& s_{L O F}=\int_{0}^{v_{L O F}} \frac{d\left(v^{2} / 2\right)}{a(v)}=\frac{1}{2 \cdot \bar{a}} \int_{0}^{v_{L O F}} d\left(v^{2}\right)=\frac{v_{L O F}^{2}}{2 \cdot \bar{a}}= \\
& =\frac{T O W \cdot v_{L O F}^{2}}{2 \cdot g \cdot \bar{F}_{n e t}}=\frac{M \cdot v_{L O F}^{2}}{2 \cdot \bar{F}_{n e t}}=\frac{E_{k, L O F}}{\bar{F}_{n e t}}
\end{aligned}
$$

Since the net force is essentially weight-independent (except for small retarding effect of rolling friction), the lighter the airplane the faster the acceleration and vice versa. However, the total energy stays conserved over equal distances.

The airborne distance of takeoff (AEO or OEI) is achieved in varying intensity of ground effect and can be estimated using the total-energy approach:

$$
s_{A B}\left(v_{S H}, S H, T O W\right)=\frac{T O W}{\bar{F}_{n e t, A B}}\left[\frac{v_{S H}^{2}-v_{L O F}^{2}}{2 \cdot g}+S H\right]
$$

During airborne $(\mathrm{AB})$ phase the airplane changes its kinetic energy from LOF to $\mathrm{SH}$ condition $\left(\mathrm{V}_{2}\right.$ when OEI, $\mathrm{V}_{3}=\mathrm{V}_{2}+10$ when AEO, or more) and its 
height potential energy from zero to $\mathrm{SH}$ (=35 ft dry or $=15 \mathrm{ft}$ wet). The total takeoff distance required (TODR) to achieve certain airspeed and height above RZ is simply, $s_{\text {Tkoff }}=s_{L O F}+s_{A B}$. Such distance cannot exceed TODA which may consist of declared TORA plus clearway, not to exceed $150 \%$ of TORA. In a sense TODR and takeoff run required (TORR) define energy state of an airplane.

The approximate $\mathrm{V}_{1 \mathrm{MAX}}=\mathrm{V}_{\text {STOP }}$ speed (AS or RTO) can be now calculated using the Accelerate-Stop Distance Required (ASDR) to be $\leq$ ASDA, which is the FAR/CS 25.109 requirement (delay is 2 seconds coasting at $V_{1}$ plus there is 1 second recognition time between engine-failure airspeed $\mathrm{V}_{\mathrm{EF}}$ and $\mathrm{V}_{1}$ ):

$$
\frac{v_{S T O P}^{2}}{2 \cdot \bar{a}_{A E O}}+v_{S T O P} \cdot t_{\text {delay }}+\frac{v_{S T O P}^{2}}{2 \cdot \bar{a}_{S T O P}} \leq A S D A
$$

Estimated ASDR is based on an engine-failure RTOs only. ASDA's correction for regulatory runway alignment for given airplane type is included. Rolling takeoff correction could be included as well. To determine $\mathrm{V}_{1, \mathrm{MAX}}=\mathrm{V}_{\mathrm{STOP}}$, a quadratic equation must be solved:

$$
\begin{aligned}
& A \cdot v_{S T O P}^{2}+B \cdot v_{S T O P}+C=0 \\
& A=\frac{T O W}{2 \cdot g}\left(\frac{1}{\bar{F}_{A E O}}+\frac{1}{\bar{F}_{S T O P}}\right) \\
& B=t_{\text {delay }} \\
& C=-A S D A_{\text {corr }}
\end{aligned}
$$

With the unique real and positive solution:

$$
v_{\text {STOP }}=\frac{-B+\sqrt{D}}{2 \cdot A}>0 \quad D=B^{2}-4 \cdot A \cdot C>0
$$

The minimum $\mathrm{V}_{1 \mathrm{MIN}}=\mathrm{V}_{\mathrm{GO}}\left(>\mathrm{V}_{\mathrm{MCG}}\right)$ (minimum control speed - ground) for continued takeoff is found from TODA considerations. In the case of short, or no, clearway, TODA is more restrictive than TORA and that is the only case considered now. However, it presents no difficulty at all to incorporate TORA calculations. It is also not difficult to include wind effects, but that step will be 
avoided at this point to reduce overall complexity. TAS can be easily converted into CAS by: $C A S=T A S \times \sqrt{\sigma}$.

In the case of continued takeoff (accelerate-go), the airplane must reach some minimum $\mathrm{V}_{\mathrm{GO}}$ speed with $\mathrm{AEO}$ and then after suffering sudden engine failure it is possible to continue OEI and cross $\mathrm{SH}$ at $35 \mathrm{ft}$ (dry) and $\mathrm{V}_{2}$. Thus, in terms of total energy:

$$
v_{G O}\left(v_{S H}, S H, T O W\right) \geq \sqrt{\left(\frac{\bar{a}_{A E O}-\bar{a}_{O E I}}{2 \bar{a}_{A E O} \bar{a}_{O E I}}\right) \cdot\left[\frac{v_{S H}^{2}}{2 \bar{a}_{O E I}}-\left(T O D A_{c o r r}-\frac{S H}{\bar{\gamma}_{S H}}\right)\right]}
$$

Where the corrected TORA for airplane runway alignment was used. The $\mathrm{V}_{\mathrm{SH}}=\mathrm{V}_{2 \mathrm{MIN}}$ is calculated as speed $20 \%$ above the stall speed (or $13 \%$ above $\mathrm{V}_{\mathrm{SR}}$ ) in a given takeoff configuration. It is clear from Equation 16 that $\mathrm{V}_{\mathrm{GO}}$ increases approximately as a square-root of TOW.

The calculations of $\mathrm{V}_{\mathrm{STOP}}$ and $\mathrm{V}_{\mathrm{GO}}$ speeds as a function of TOW for a Gulfstream IV - type airplane are shown in Figure 5. From there it follows that FLLTOW $\left(\mathrm{V}_{\mathrm{STOP}}=\mathrm{V}_{\mathrm{GO}}=\mathrm{V}_{1}\right)$ is about $64,200 \mathrm{lb}$ with $\mathrm{V}_{1}$ of 132 knots (CAS) for given air temperature, altitude, and Balanced Field Condition/Length (BFC/BFL). Any acceptable decision/action speed must satisfy: $v_{M C G}<v_{1} \leq v_{R} \leq v_{M B E}$.

\section{Discussion of Results}

Another way to look at the ASDA and TODA (or TORA) is in terms of aircraft total (specific) energy. Total aircraft takeoff energy can be approximated by its height $(\mathrm{SH})$ above RZ and specific kinetic energy (height) " $v_{S H}^{2} / 2 g$ ”. A functional relationship is also presented with the last equation shown in Figure 2. ASDR defines distance to achieve certain maximum kinetic energy and then transform it into heat irreversibly during RTO. On the other hand, TODR/TORR define total energy (height and speed) of just airborne aircraft at $\mathrm{SH}$.

CLTOW OEI takeoff will normally need TODR less than TODA. If one loads the aircraft to FLLTOW ( $\leq$ MSTOW), the airplane will accomplish OEI AG takeoff and cross $\mathrm{SH}$ at $\mathrm{V}_{2}$ but it would not comply with the climb gradient. Thrust is already at maximum and the flap setting is chosen. The only way to increase climb angle (gradient) is to reduce drag (increased $E$ ). Thus, the excess of runway (TODA minus TODR) is used to achieve (higher) $V_{2 i}$ to increase MATOW and still meet required still-air and obstacle climb gradients. 
The mechanics of improved- $\mathrm{V}_{2}$ takeoff-climb maneuver is illustrated in Figure 6. The FLLTOW is defined with point " $A$ " but that weight exceeds CLTOW and thus not meeting required GOC. The CLTOW which meets required GOC defines unbalanced takeoff condition with the speed-range existing between $\mathrm{V}_{\mathrm{GO}}$ speed ("B") and $\mathrm{V}_{\text {STOP }}$ speed ("C"). If one sets $\mathrm{V}_{1}=\mathrm{V}_{\mathrm{GO}}$ at "B" then the airplane will just acquire the basic minimum continued OEI energy at required $\mathrm{SH}$ and $\mathrm{V}_{2}$ to meet the required climb gradient. If pilot decides to abort takeoff at " $\mathrm{B}$ " then a lot of unused ASDA will exist. If one choses $\mathrm{V}_{1}=\mathrm{V}_{\mathrm{STOP}}$ (at point " $\mathrm{C}$ ") then the entire ASDA will be used for RTO. The airplane could have excess energy for climb if higher $V_{2}$ is also chosen with higher $V_{1}=V_{\text {STOP. It would be wiser though }}$ to use $\mathrm{V}_{1}$ closer to point " $\mathrm{B}$ " $\left(\mathrm{V}_{\mathrm{GO}}\right)$ for turbofan-type airplane as high-speed aborts are a tricky matter and there is plenty of excess trust for AG takeoff (Daidzic, 2013b). The counter-argument would be that it is safer to overrun runway at 20-30 knots while decelerating during RTO then hit obstacles while airborne in initial climb or stall in ground effect at $140+$ knots.

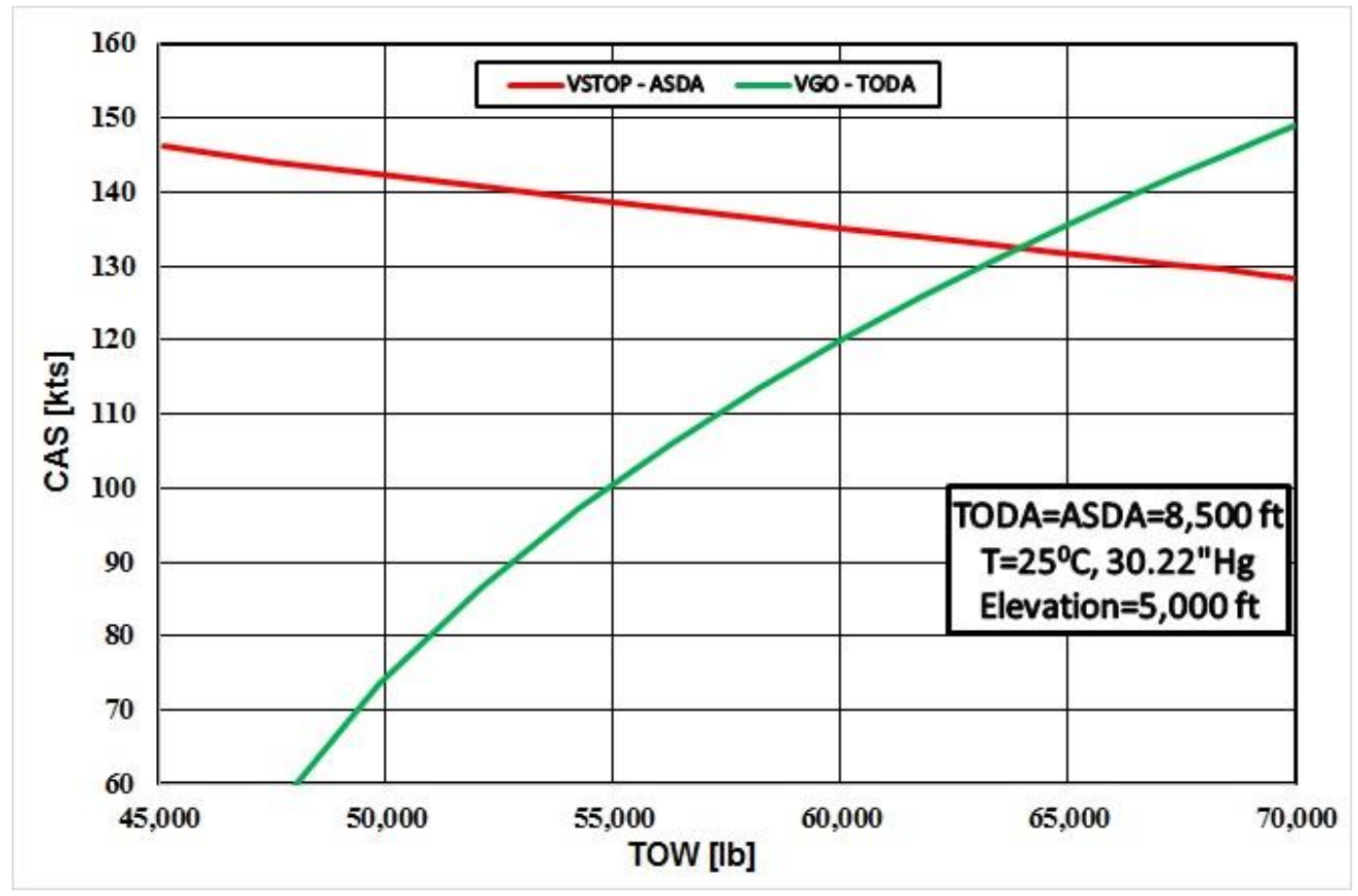

Figure 5. Calculated minimum $\left(\mathrm{V}_{\mathrm{GO}}\right)$ and maximum $\left(\mathrm{V}_{\mathrm{STOP}}\right)$ "action" speeds $\left(\mathrm{V}_{1}\right)$ as a function of TOW for declared runway-alignment-corrected ASDA and TODA distances for an airplane with similar characteristics as Gulfstream IV. 
Between the two extremes of CLTOW (legal but unprofitable) and FLLTOW (profitable but illegal) one finds TOWi for which ASDA and TODA intersect at point " $\mathrm{D}$ " where $\mathrm{V}_{1 \mathrm{BAL}}=\mathrm{V}_{\mathrm{GO}}=\mathrm{V}_{\mathrm{STOP}}$. The airplane can stop within ASDA while new TODA will ensure that $\mathrm{SH}$ will be reached at increased $\mathrm{V}_{2 \mathrm{i}}$ which is equal to the old $\mathrm{V}_{2}$ (at FLLTOW) plus the speed increment of, typically, 10-20 knots. New faster $\mathrm{V}_{1 \mathrm{i}}$ (must still meet ASDA when RTO) will enable higher $V_{R i}, V_{L O F i}$ and $V_{2 i}$ satisfying the required climb gradient. In a sense one arrives at a new "balanced condition" where the original FLLTOW was sacrificed to increase the original CLTOW. The total aircraft energy at FLLTOWi=CLTOWi and the old FLLTOW remains the same for fixed SH. Weight reduction in FLLTOW was traded for higher $\mathrm{V}_{2 \mathrm{i}}$ in TOWi.

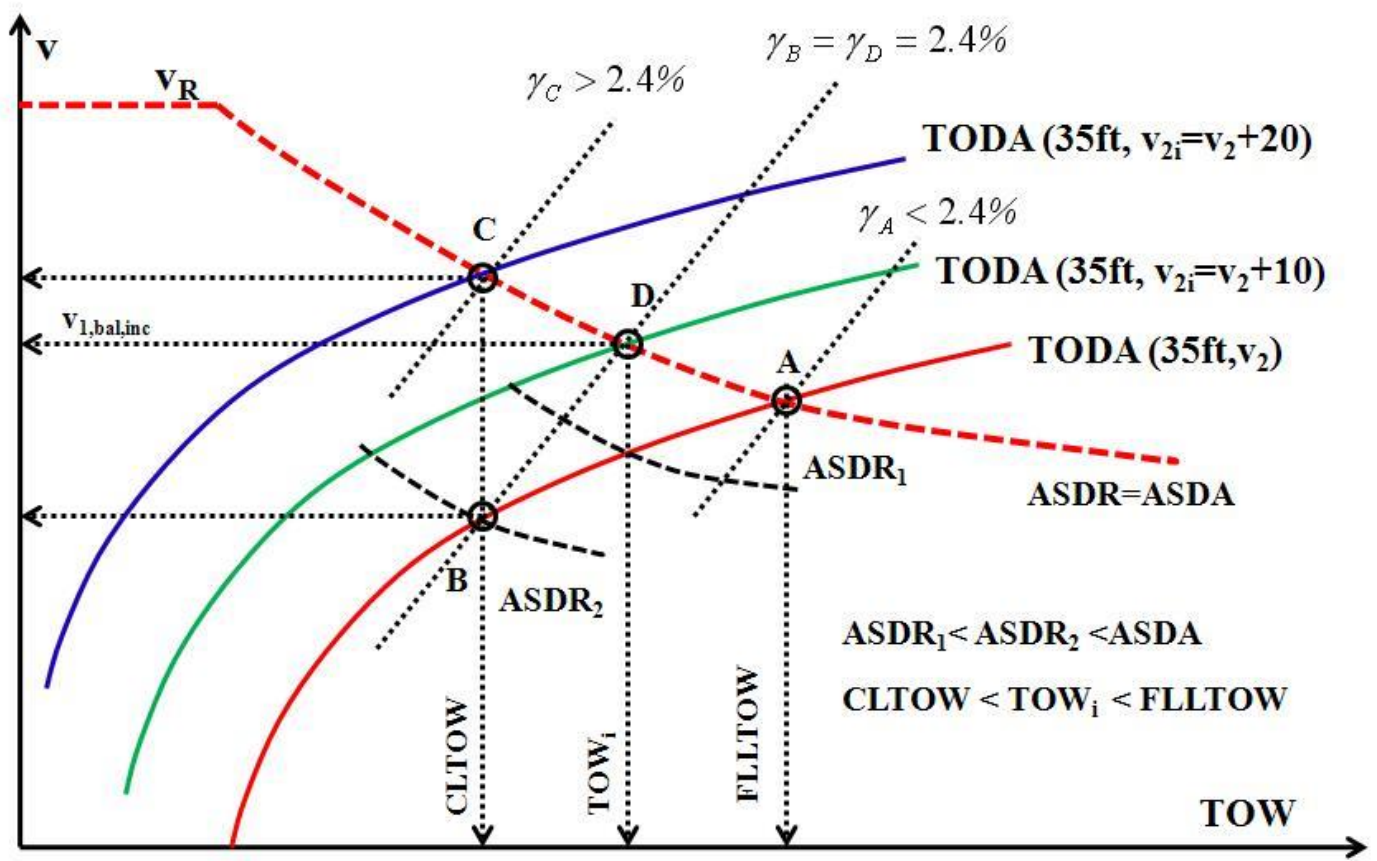

Figure 6. Overspeed takeoff for increased TOWi > CLTOW and given airfield distances. Not to scale.

A diagram showing climb speeds $\left(\mathrm{V}_{2}\right)$ required for given in-flight climb weights and fixed GOCs for a corporate jet similar to Gulfstream IV was created using our in-house designed performance programs and shown here in Figure 7. Basically, to lift more weight the faster the airplane must be moving (both in sense of KCAS and KTAS). The big question is if available runway will let us achieve such higher speeds. The graph shows the range of $V_{2}$ speeds ("backside" of the excess-thrust curve) for each particular airplane weight meeting specific 
climb gradients. This climb- $\mathrm{V}_{2}$ can be compared with the $\mathrm{TOWi}-\mathrm{V}_{2 \mathrm{i}}$ required to meet overspeed TODA/TORA limitation.

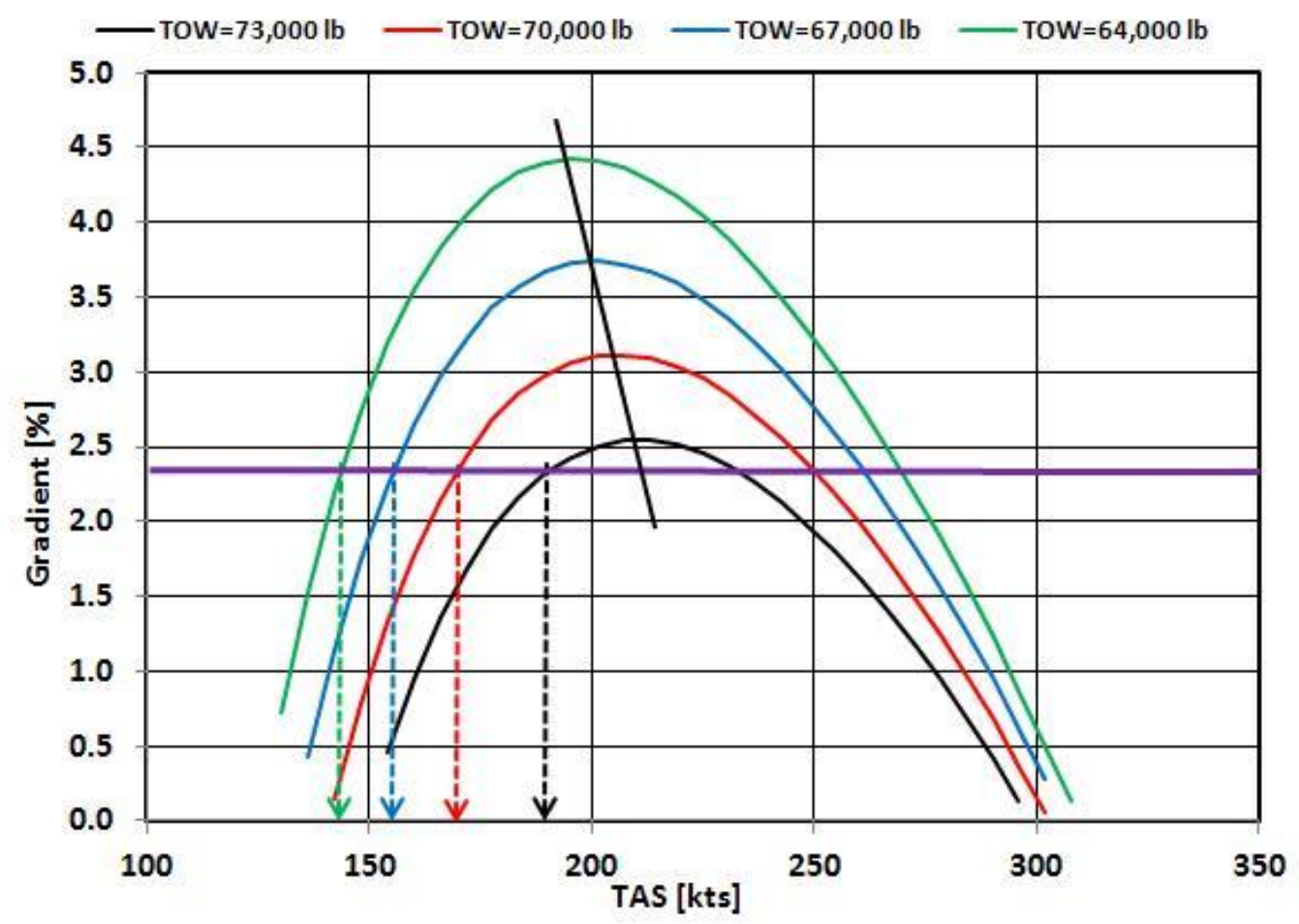

Figure 7. Climb gradient as function of TOW and TAS for given flap setting and density altitude $(\sigma=0.8)$.

Probably the best diagram to capture a combined takeoff-climb maneuver is illustrated in Figure 8. It is partly based on computations shown in Figure 4 here. It combines field and climb performance limitations in one diagram for given environmental conditions. It directly discloses TOWi and $\mathrm{V}_{2 \mathrm{i}}$ that simultaneously meet climb gradient and TODA/TORA/ASDA limitations. It clearly illustrates the improved- $\mathrm{V}_{2}$ takeoff-climb physics. As can be seen in Figure 8, the FLLTOW (point "A") meets TODR $_{3}=$ TODA limitation at normal$\mathrm{V}_{2}$, but does not produce required climb gradient. On the other hand CLTOW < FLLTOW at lower $\mathrm{V}_{2}$ will deliver the required climb gradient (WAT climb GOC of $2.4 \%$ ) but with a significant weight penalty (point "B"). Obviously, TODR 4 used is significantly shorter than TODA. Using higher $\mathrm{V}_{2}$ speeds with CLTOW (e.g., point "D") only gives higher climb-gradient for somewhat larger TODR which is not needed. The intersection (point " $\mathrm{C}$ ") of the constant-energy TODR 3 and the (constant) required climb gradient curve $(2.4 \%$ here) directly gives the 
new field- and climb-limited TOWi @ $\mathrm{V}_{2 \mathrm{i}}$. Using increased TOWi with the old$\mathrm{V}_{2}$ (point " $\mathrm{G}$ ") results in small, but insufficient, climb gradient improvement $(2.1 \%)$ and some unused TODA and still makes takeoff illegal.

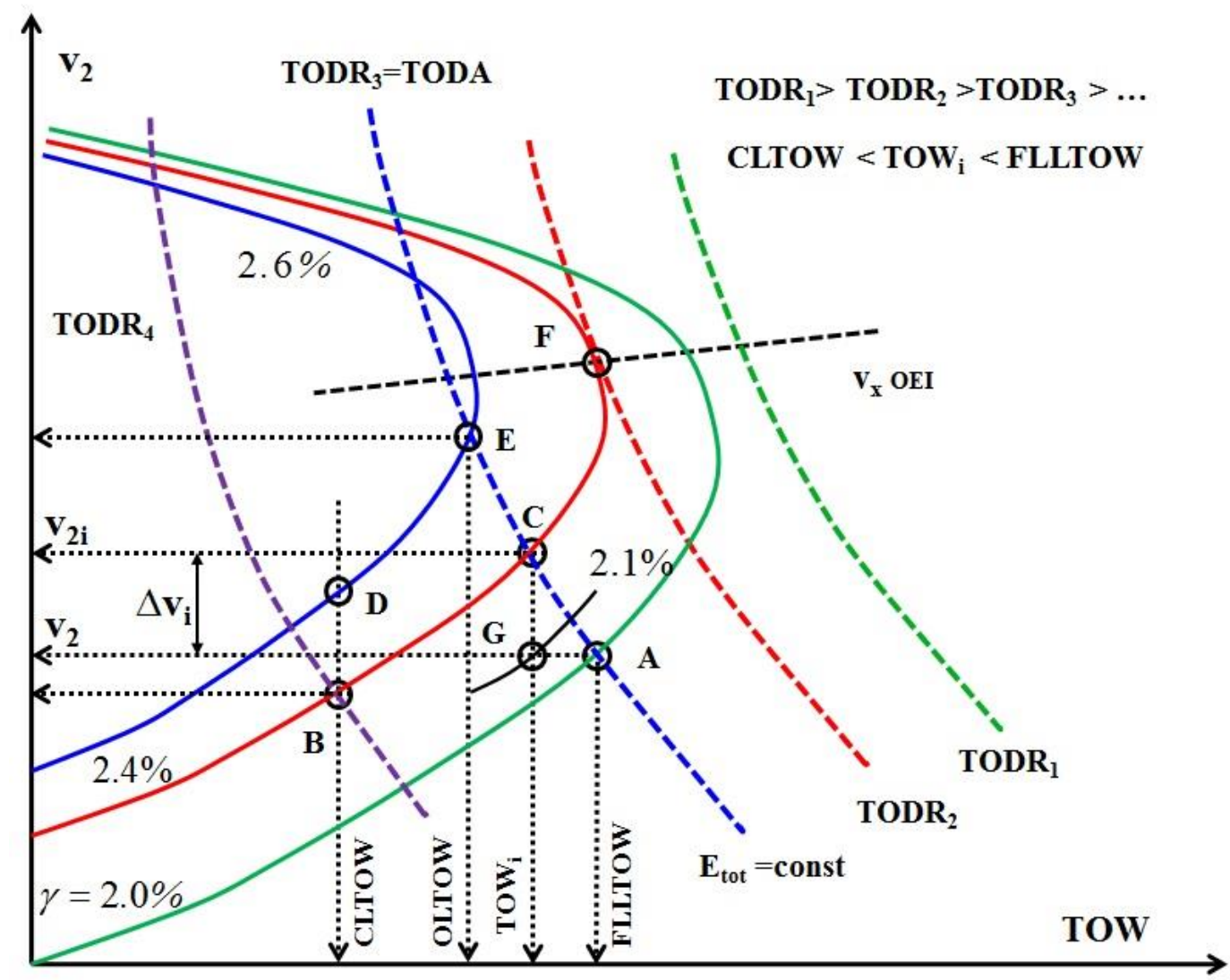

Figure 8. Overspeed takeoff for increased TOW and given airfield distances for given $\mathrm{SH}$ and $\mathrm{V}_{\mathrm{SH}}$. Not to scale.

If higher climb gradient (net and gross) is needed for obstacle-clearance than intersection of required gradient and TODA (point "E") is used. It produces OLTOW at even higher $\mathrm{V}_{2}$, thus OLTOW < TOWi. Noticeably, a region near $\mathrm{V}_{\mathrm{X}}$ speeds should be actually avoided because for modest TOW increases disproportionally longer TODA (point " $F$ ") is required. So staying on the "backside" of the excess-thrust curve about 20-30 knots below $\mathrm{V}_{\mathrm{X}}$ (or having $\mathrm{V}_{2 \mathrm{i}}=\mathrm{V}_{2}+20$ ) is a practical optimum for most improved takeoff-climb situations. Besides, other limitations will almost certainly prevent using excessive $\mathrm{V}_{2}$ 's (close to $\mathrm{V}_{\mathrm{X}}$ ). 
To find the required speed increment one relies on the conservation of kinetic energy as potential energy part is very small (Equation 11):

$$
F L L T O W \cdot v_{2}^{2}=T O W_{i} \cdot v_{2 i}^{2} \quad T O W_{i}=F_{L L T O W}=C L T O W_{i}
$$

where, $v_{2 i}^{2}=\left(v_{2}+\Delta v_{i}\right)^{2}$, resulting in:

$$
\Delta v_{i}=v_{2} \cdot\left(\sqrt{\frac{F L L T O W}{T O W_{i}}}-1\right)^{2} \quad v_{2 i}=v_{2}+\Delta v_{i}
$$

Utilizing a simple bracketing method the solution is rapidly located in few iterations. Of course, it is easy to encode this procedure in any programming language (e.g., Matlab ${ }^{\mathrm{TM}}$, Fortran, Basic, $\mathrm{C}++$, etc.) and/or design diagrams for specific airplane make $\&$ model similar to illustration shown in Figure 8.

To demonstrate how this procedure works, let us imagine a twin-engine jet with FLLTOW of 200,000 lb with $\mathrm{V}_{2}$ of 160 knots, but having maximum WATclimb (OEI) GOC of only $2 \%$ and thus unacceptable. Assume also that existing environmental conditions and altitude restrict CLTOW to only 140,000 lb with plenty of TODA unused then. The airplane is climb-WAT limited and huge weight penalty is paid. So an overspeed or improved- $\mathrm{V}_{2}$ takeoff is in order. The first iteration includes halving the range between the original FLLTOW and CLTOW. This results in 170,000 $\mathrm{lb}$ for which $\mathrm{V}_{2 \mathrm{i}}$ and $\Delta \mathrm{V}_{\mathrm{i}}$ are 173.5 and 13.5 knots respectively using Equation 18. Assume that at the updated TOWi, GOC of $2.25 \%$ is achieved. Therefore, one needs to reduce the first-iteration TOWi some more. Now the region between 140,000 and 170,000 $\mathrm{lb}$ is halved and one arrives at the updated TOWi of $155,000 \mathrm{lb}$ with the new $\mathrm{V}_{2 \mathrm{i}}$ and $\Delta \mathrm{V}_{\mathrm{i}}$ of 181.7 and 21.7 knots respectively. This TOW will result in OEI still-air WAT-climb GOC of $2.45 \%$ and thus more than required. So TOWi can be increased to $160,000 \mathrm{lb}$, which at $\mathrm{V}_{2 \mathrm{i}}$ and $\Delta \mathrm{V}_{\mathrm{i}}$ of 179 and 19 knots respectively exactly meets the required $2.4 \%$ WAT GOC. Note that the original CLTOW/MATOW limit has risen by $20,000 \mathrm{lb}$ which is approximately equivalent to 100 average FAA-passengers with luggage.

Essentially, two simultaneous nonlinear equations with two unknowns can be fully solved by using appropriate numerical methods. A quick solution for this problem can be obtained by, for example, Newton-Raphson numerical nonlinear equations solver for finding real roots (zeroes) from a set of simultaneous nonlinear equations. The two solutions converge rapidly to unknown TOWi and $\mathrm{V}_{2 \mathrm{i}}$ for appropriate initial guesses: 


$$
\begin{aligned}
& T O W_{i}=\frac{T\left(\sigma, v_{2 i}\right)-D\left(\sigma, v_{2 i}, T O W_{i}\right)}{\gamma_{\text {required }}} \\
& v_{2 i}=v_{2} \cdot \sqrt{\frac{F L L T O W}{T O W_{i}}}
\end{aligned}
$$

Accordingly, iterative adjustment of TOWi and $\mathrm{V}_{2 \mathrm{i}}$ to simultaneously meet required GOC and TODA is achieved. One could do similar computations using Equation 19 for OLTOW scenario (provided higher GOC is required) and account for wind effect as well. While this analytical-numerical method is not an (FAA/EASA) approved procedure, it can be used to quickly estimate parameters of overspeed takeoffs for any FAR/CS 25 transport-category airplane. The profitability and economic analysis of overspeed takeoffs can be based on this analytical method as well.

Other limitations associated with (increased) $\mathrm{V}_{1 \mathrm{i}}$ and $\mathrm{V}_{\mathrm{LOFi}}$ may be posed by the airplane brake-energy limitation $\left(\mathrm{V}_{\mathrm{MBE}}\right)$ or the maximum tire speed restriction. This could become restrictive if the density altitude is very high, runway has down-slope in the direction of ground roll and/or takeoff is performed with tailwind. Different takeoff configurations will require separate computations of overspeed parameters.

When the actual TOW is not field-, climb- or obstacle-limited it is often possible to use reduced thrust Assumed Temperature Method (ATM) and/or derated thrust (D-TO1/D-TO2, etc.) in combination with the improved- $\mathrm{V}_{2}$ climb (Daidzic, 2012). Since unused TODA/ASDA exists thrust can be reduced until the first limitation is met in terms of FLLTOW, CLTOW, OLTOW or 25\% (unless approved for lower) thrust reduction. More on combined reduced thrust overspeed takeoff will be discussed in subsequent article.

\section{Conclusions}

The physics of overspeed takeoffs is very complex. A manufacturer and a regulatory agency relies on measured performance in instrumented prototypes which is expensive and time-consuming procedure. Inherent performance margins and safety cushions are included in operational regulations utilizing FAR/CS 25 transport-categories airplanes. Consideration of essential overspeed-takeoff mechanics and principal parameters was examined in this article. Aerodynamic efficiency always decreases for any flap deployment at constant speed. Takeoff flap-setting seeks to optimize between marked reduction in stalling speed and increase in aerodynamic drag, hurting subsequent airplane climb gradient. Only 
few discrete forward and leading flap settings are possible in real airplanes and global TOW maximization cannot be achieved in practice. If the airplane is climb or obstacle limited, any unused TODA/TORA can be utilized to increase airplane kinetic energy by increasing performance speeds while reducing drag and increasing climb gradients. The TOW and speed increase above CLTOW goes until the airplane becomes simultaneously climb- and field-limited. This technique can be used for obstacle-limited TOWs as well, but the actual location and height of obstacles need to be known so that TOW can be specifically maximized while meeting all other limitations. Overspeed takeoffs can be especially beneficial for more distant obstacles as higher $\mathrm{V}_{2}$ delivers steeper climb gradients. Unused runway distance can be invested to increase aircraft's total (specific) energy. Transforming unused runway distance into airplane kinetic energy is far more important than gaining altitude above regulatory minimum at SH as increased climb speeds lead to lower drag resulting in steeper steady climbs. Excessive $\mathrm{V}_{2 \mathrm{i}}$, close to $\mathrm{V}_{\mathrm{X}}$, requires disproportionally longer TODA for petite increase in TOW. Clearly tire-speed and maximum brake-energy could become limiting at increased ground speeds. Improved- $\mathrm{V}_{2}$ can be combined with the reduced thrust takeoffs. Improved- $\mathrm{V}_{2}$ takeoffs abiding by all other limitations are important tool in increased safety and profitability of operations. A set of simultaneous nonlinear equations describing overspeed takeoff can be rapidly solved using, for example, Newton-Raphson method which can be easily encoded in appropriate programming language and calculations automated. However, manually performed iteration steps also lead to relatively quick solution of the problem. The next step will be to compare the performance figures provided in transport-category airplane AFMs with the predictions obtained using this totalenergy based analytical method, in order to verify its relevance and accuracy. 


\section{Author Bios}

Dr. Nihad E. Daidzic is president of AAR Aerospace Consulting, L.L.C. He is also a full Professor of Aviation, adjunct professor of Mechanical Engineering, and research graduate faculty at Minnesota State University, Mankato. He was formerly a staff scientist at the National Microgravity Research Center and the National Center for Space Exploration and Research at NASA Glenn Research Center in Cleveland, OH. He also held various faculty appointments at Vanderbilt University, University of Kansas, and Kent State University. His current research interest is in theoretical, experimental, and computational fluid dynamics, aircraft stability, control, and performance, mechanics of flight, piloting techniques, and aerospace propulsion. Dr. Daidzic is CFII and ATP with flight experience in airplanes, helicopters, and gliders. 


\section{References}

Anderson, J. D. Jr. (1999). Aircraft performance and design. New York, NY: McGraw-Hill.

Asselin, M. (1997). An Introduction to Aircraft Performance. Reston, VA: American Institute for Aeronautics and Astronautics (AIAA).

Daidzic, N. E., \& Shrestha, J. (2008). Airplane Landing Performance on Contaminated Runways in Adverse Conditions. Journal of Aircraft, 45, 2131-2144. doi: 10.2514/1.38056

Daidzic, N. E. (2008, December). When go-around is impossible - defining the point of no return. Professional Pilot, 42(12), 110-113.

Daidzic, N. E. (2009a, September). Avoiding veer-off accidents on contaminated runways, Professional Pilot, 43(9), 54-58.

Daidzic, N. E. (2009b, December). Avoiding overrun accidents on contaminated runways, Professional Pilot, 43(12), 104-107.

Daidzic, N. E. (2011a, March). Dealing with Contaminated Runways. The Journal for Civil Aviation Training (CAT), 2/2011, 29-32.

Daidzic, N. E. (2011b, May). Point of Flare - The Last Five Seconds, Professional Pilot, 45(5), 110-114.

Daidzic, N. E. (2012, September). Jet engine thrust ratings, Professional Pilot, 46(9), 92-96.

Daidzic, N. E. (2013a, August). T/O overruns and veer-offs on slippery runways with crosswinds, Professional Pilot, 47(8), 54-58.

Daidzic, N. E. (2013b, November). Aircraft tests arrive at numbers pilots need for safe operations, Professional Pilot, 47(11), 100-104.

Eshelby, M. E. (2000). Aircraft performance: Theory and practice. Boston, MA: Elsevier. 
European Aviation Safety Agency (2007). Certification Specifications for Large Aeroplanes CS-25 (Amendment 3, 19 September). Cologne, Germany: Author.

Holt, M. J., \& Poynor, P. J. (2006). Air carrier operations. Newcastle, WA: Aviation Supplies \& Academics.

Jeppesen. (2007). Performance. (JAA ATPL Training, Edition 2, JA 310109-002, Book 9, JAR Ref. 032, ISBN 0-88487-496-6). Neu-Isenburg, Germany: Atlantic Flight Training, Ltd., Sanderson Training products, Jeppesen $\mathrm{GmbH}$.

Joint Aviation Authorities. (2007). JAR-OPS 1: Commercial Air Transportation (Aeroplanes) (Amendment 13, 1 May). Brussels, Belgium: Author.

Mair, W. A., \& Birdsall, D. L. (1992). Aircraft performance. Cambridge, UK: Cambridge University Press.

McCormick, B. W. (1995). Aerodynamics, aeronautics and flight mechanics. 2nd ed., New York, NY: John Wiley \& Sons.

Padilla, C. E. (1996). Optimizing jet transport efficiency: Performance, operations, and economics. New York, NY: McGraw-Hill.

Swatton, P. J. (2008). Aircraft performance: Theory and practice for pilots. 2nd ed., Chichester, UK: John Wiley \& Sons.

US Department of Transportation, Federal Aviation Administration. (1994). Takeoff Safety Training Aid (Advisory Circular AC 120-62). Washington, DC: Author.

US Department of Transportation, Federal Aviation Administration. (2013). Part 25, Airworthiness Standards: Transport Category Airplanes. Washington, DC: Author. 